\title{
Effects of acute kidney injury after liver resection on long-term outcomes
}

\author{
Seiji Ishikawa ${ }^{1}$, Manami Tanaka $^{1}$, Fumi Maruyama ${ }^{2}$, Arisa Fukagawa ${ }^{1}$, \\ Nobuhiro Shiota ${ }^{1}$, Satoshi Matsumura ${ }^{3}$, and Koshi Makita ${ }^{1}$ \\ Departments of ${ }^{1}$ Anesthesiology, ${ }^{2}$ Critical Care Medicine, and ${ }^{3}$ Hepatobiliary and Pancreatic Surgery, Tokyo \\ Medical and Dental University, Graduate School of Medical and Dental Sciences, Tokyo, Japan
}

Background: To investigate the effects of acute kidney injury (AKI) after liver resection on the long-term outcome, including mortality and renal dysfunction after hospital discharge.

Methods: We conducted a historical cohort study of patients who underwent liver resection for hepatocellular carcinoma with sevoflurane anesthesia between January 2004 and October 2011, survived the hospital stay, and were followed for at least 3 years or died within 3 years after hospital discharge. AKI was diagnosed based on the Acute Kidney Injury Network classification within 72 hours postoperatively. In addition to the data obtained during hospitalization, serum creatinine concentration data were collected and the glomerular filtration rate (GFR) was estimated after hospital discharge. Results: AKI patients $(63 \%, \mathrm{P}=0.002)$ were more likely to reach the threshold of an estimated GFR (eGFR) of $45 \mathrm{ml} /$ $\mathrm{min} / 1.73 \mathrm{~m}^{2}$ within 3 years than non-AKI patients (31\%) although there was no significant difference in mortality (33\% vs. 29\%). Cox proportional hazard regression analysis showed that postoperative AKI was significantly associated with the composite outcome of mortality or an eGFR of $45 \mathrm{ml} / \mathrm{min} / 1.73 \mathrm{~m}^{2}$ (95\% CI of hazard ratio, 1.05-2.96, P = 0.033), but not with mortality $(P=0.699)$, the composite outcome of mortality or an eGFR of $60 \mathrm{ml} / \mathrm{min} / 1.73 \mathrm{~m}^{2}(\mathrm{P}=0.347)$.

Conclusions: After liver resection, AKI patients may be at higher risk of mortality or moderate renal dysfunction within 3 years. These findings suggest that even after discharge from the hospital, patients who suffered AKI after liver resection may need to be followed-up regarding renal function in the long term.

Key Words: Acute kidney injury, Hepatectomy, Long term adverse effects, Perioperative management.

Corresponding author: Seiji Ishikawa, M.D., Ph.D.

Department of Anesthesiology, Juntendo University, Graduate School of Medicine, 2-1-1, Hongo, Bunkyo-ku, Tokyo 113-0033, Japan

Tel: 81-3-3813-3111, Fax: 81-3-5689-3820

Email: seiji.ishikawa.juntendo@gmail.com

ORCID: https://orcid.org/0000-0002-5044-7789

It was presented at the 61th Annual Meeting of the Japanese Society of Anesthesiologists, May 2014, PACIFICO Yokohama, Yokohama, Japan.

Received: December 2, 2016.

Revised: February 4, 2017 (1st); February 20, 2017 (2nd).

Accepted: February 20, 2017.

Korean J Anesthesiol 2017 October 70(5): 527-534

https://doi.org/10.4097/kjae.2017.70.5.527

\section{Introduction}

Postoperative acute kidney injury (AKI) accounts for $18-47 \%$ of all hospital-acquired AKIs [1,2]. Since the introduction of the first consensus definition of AKI (Risk, Injury, Failure, Loss, and End-stage renal disease [RIFLE] [3]) in 2004, and the modified version of the classification proposed by the Acute Kidney Injury Network (AKIN) in 2007 [4], AKI has been shown to be associated with prolonged hospital stays [5-7], and increased morbidity and mortality $[5,6,8-12]$ after cardiac $[5,8,9,11]$ and non-cardiac surgery $[6,7,9,10,12]$. While it is widely accepted that AKI worsens outcomes during hospitalization, there is little information on the effects of postoperative AKI on long-term

(c) This is an open-access article distributed under the terms of the Creative Commons Attribution Non-Commercial License (http://creativecommons.org/ licenses/by-nc/4.0/), which permits unrestricted non-commercial use, distribution, and reproduction in any medium, provided the original work is properly cited. 
outcomes $[13,14]$. To our knowledge, no study has investigated the effects of AKI on the long-term outcome of patients who have undergone major abdominal surgery.

Recently, the relationship between AKI and long-term decline in renal function has attracted attention. Although AKI has long been considered a benign, reversible process, researchers have demonstrated that the risks of progression to chronic kidney disease (CKD) and end-stage renal disease (ESRD) may increase, even if renal function recovers completely after AKI in non-surgical settings [15]. It is not clear whether postoperative AKI in non-cardiac and non-transplantation settings worsens renal function in the long term after hospital discharge.

Liver resection is major abdominal surgery and is rarely associated with massive bleeding [16]. If the hypovolemia due to excessive blood loss continues and the reduction in oxygen delivery remains uncorrected, the renal medulla may be susceptible to ischemic acute tubular necrosis [17]; consequently, these patients may experience AKI. This study investigated the effects of AKI within 72 hours after liver resection for hepatocellular carcinoma (HCC) on the long-term outcomes (within 3 years after discharge).

\section{Materials and Methods}

The study was approved by the Clinical Research Ethics Board (No. 1683, January 20, 2014), and the need for informed consent was waived. This report is based on our single-center historical cohort study of patients who underwent liver resection and adheres to the Strengthening the Reporting of Observational Studies in Epidemiology guidelines [18].

\section{Patient inclusion and data collection}

We conducted a historical cohort study of patients who underwent liver resection for HCC with sevoflurane between January 2004 and October 2011, survived the hospital stay, and were followed for at least 3 years or died within 3 years after hospital discharge. Part of a database comprising 642 patients who underwent liver resection at our hospital was used to obtain data for this study. A previous study [19] based on the same database showed that postoperative AKI was associated with longer hospital stays and higher mortality rates during hospitalization. This database included patient, surgical, anesthetic, and laboratory data, manually abstracted from the patients' electronic charts. The collected data included age, sex, height, body weight, body mass index, American Society of Anesthesiologists physical status, and history of hypertension, ischemic heart disease, atrial fibrillation, cerebrovascular disease, diabetes mellitus, hyperlipidemia, chronic obstructive pulmonary disease, liver cirrhosis, and peripheral vascular disease. Preoperative use of the following medications was recorded: non-steroidal antiinflammatory drugs, angiotensin-converting enzyme inhibitors, angiotensin II receptor blockers, statins, steroids, or diuretics. The following surgical and anesthetic factors were recorded: surgical procedure, emergency or elective surgery, thoracic epidural anesthesia, maintenance anesthetic agent, duration of anesthesia and surgery, volume and type of intraoperative fluids administered (crystalloid or colloid), and lowest systolic blood pressure (SBP) during anesthesia. Blood loss was calculated from the increase in weight of the surgical gauze used, the volume of blood and saline suctioned, and the volume of saline used in the surgical field. Major liver resection was defined as a resection of at least three Couinaud liver segments. The colloid solution used during the study period consisted of $6 \%$ hydroxyethyl starch (HES) 70/0.5 (Hespander ${ }^{\circledR}$, Fresenius Kabi Japan, Tokyo, Japan) and $5 \%$ albumin. Intraoperative transfusions of red blood cells, fresh frozen plasma, and platelets were recorded. One unit of each blood component was derived from $200 \mathrm{ml}$ of whole blood. Laboratory values obtained from the electronic charts included hemoglobin, serum creatinine concentration ( $\mathrm{sCr}$ ), albumin, total bilirubin, transaminase enzymes, and 15-minute indocyanine green retention rate (ICG-R15).

In addition to the data used in our previous study [19], sCr data after hospital discharge were collected for 3 years or until the patients died. Cancer stage data was collected according to the tumor, node, metastasis (TNM) staging of the American Joint Committee on Cancer/Union Internationale contre le Cancer. The glomerular filtration rate (GFR) was estimated using the formula developed for Japanese adults and adjusted for each $1.73 \mathrm{~m}^{2}$ of body surface area: estimated GFR (eGFR) (ml/ $\left.\mathrm{min} / 1.73 \mathrm{~m}^{2}\right)=194 \times \mathrm{sCr}(\mathrm{mg} / \mathrm{dl})^{(-1.094)} \times \operatorname{Age}(\mathrm{yr})^{(-0.287)} \times 0.739$ (if female) [20].

\section{Definitions and outcomes}

This study investigated the effects of AKI within 72 hours after surgery on long-term outcomes after hospital discharge. AKI was identified based on the AKIN creatinine criteria [4] and defined as an abrupt (within 48 hours) absolute sCr increase of $\geq 0.3 \mathrm{mg} / \mathrm{dl}$, or a percentage $\mathrm{sCr}$ increase of $\geq 50 \%$ (1.5-fold from baseline) (Table 1). Urine output data were not used for diagnosis, as these data were inconsistently charted depending on the site of postoperative recovery.

Outcome variables included mortality, renal dysfunction (eGFR of 45 and $60 \mathrm{ml} / \mathrm{min} / 1.73 \mathrm{~m}^{2}$ ), a composite outcome of mortality or eGFR $\leq 60 \mathrm{ml} / \mathrm{min} / 1.73 \mathrm{~m}^{2}$, and a composite outcome of mortality or eGFR $\leq 45 \mathrm{ml} / \mathrm{min} / 1.73 \mathrm{~m}^{2}$. The stages of CKD are usually based on measured or estimated GFR thresholds of $90,60,45,30$, and $15 \mathrm{ml} / \mathrm{min} / 1.73 \mathrm{~m}^{2}$ [21]. We assumed that an eGFR of 60 and $45 \mathrm{ml} / \mathrm{min} / 1.73 \mathrm{~m}^{2}$ represented mild and 
Table 1. AKIN Creatinine Criteria for the Diagnosis of AKI

Stage $1 \quad 150-200 \%$ increase in $\mathrm{sCr}$ or increase $\geq 0.3 \mathrm{mg} / \mathrm{dl}$ from baseline.

Stage $2 \quad 200-300 \%$ increase in $\mathrm{sCr}$.

Stage $3>300 \%$ increase in $\mathrm{sCr}$ from baseline or $\mathrm{sCr} \geq 4.0 \mathrm{mg} / \mathrm{dl}$ with an acute rise of $\geq 0.5 \mathrm{mg} / \mathrm{dl}$.

Patients who receive RRT are considered to have met the criteria for stage 3 irrespective of the stage that they are in at the time RRT commenced.

AKIN: Acute Kidney Injury Network, AKI: acute kidney injury, sCr: serum creatinine concentration, RRT: renal replacement therapy.

moderate CKD, respectively. We assessed whether each aforementioned outcome occurred in each patient at 1,2 , and 3 years after discharge.

As one purpose of this study was to determine whether postoperative AKI was a risk factor for mortality within 3 years after discharge, our sample size was selected to help ensure stability around the point estimates in our final multivariate model. To avoid overfitting our final outcome model, no less than eight outcome events would be required per covariate of interest. Therefore, to fit a model with eight covariates at maximum, we would require 64 outcome events. Based on an estimated $50 \%$ of patients being missing over the 3 years after discharge, an estimated $70 \%$ of patients who underwent surgery for HCC, and an estimated $40 \%$ mortality rate in the 3 years after discharge (determined by a chart review of 100 patients after liver resection), we calculated that we would need approximately 460 patients. We assumed that we had sufficient patients for a multivariate analysis because we already had 642 patients in our database [19].

\section{Statistical analysis}

The null hypothesis for this study was that there would be no difference in long-term outcomes (mortality, renal dysfunction [eGFR of 45 and $60 \mathrm{ml} / \mathrm{min} / 1.73 \mathrm{~m}^{2}$ ], composite outcome of mortality or eGFR $\leq 60 \mathrm{ml} / \mathrm{min} / 1.73 \mathrm{~m}^{2}$ and composite outcome of mortality or eGFR $\leq 45 \mathrm{ml} / \mathrm{min} / 1.73 \mathrm{~m}^{2}$ ) between AKI and non-AKI patients. We decided to include the composite outcomes as outcome variables because some patients died at home before being identified as having a low eGFR. Demographic data, comorbidities, preoperative medications, and anesthesia and surgical data were compared between the AKI and non-AKI patients using the entire cohort. The aforementioned outcome variables were compared between the AKI and non-AKI patients at 1,2, and 3 years after discharge.

Continuous variables were summarized as the median (25th and 75 th percentiles) or the mean $\pm \mathrm{SD}$. Categorical variables were summarized as frequency (percentage). Normally and non-normally distributed continuous data were analyzed using Student's two-sample t-test and the Wilcoxon rank-sum test, respectively. Categorical data were analyzed using Fisher's exact test.

Multivariate Cox proportional hazards regression was used

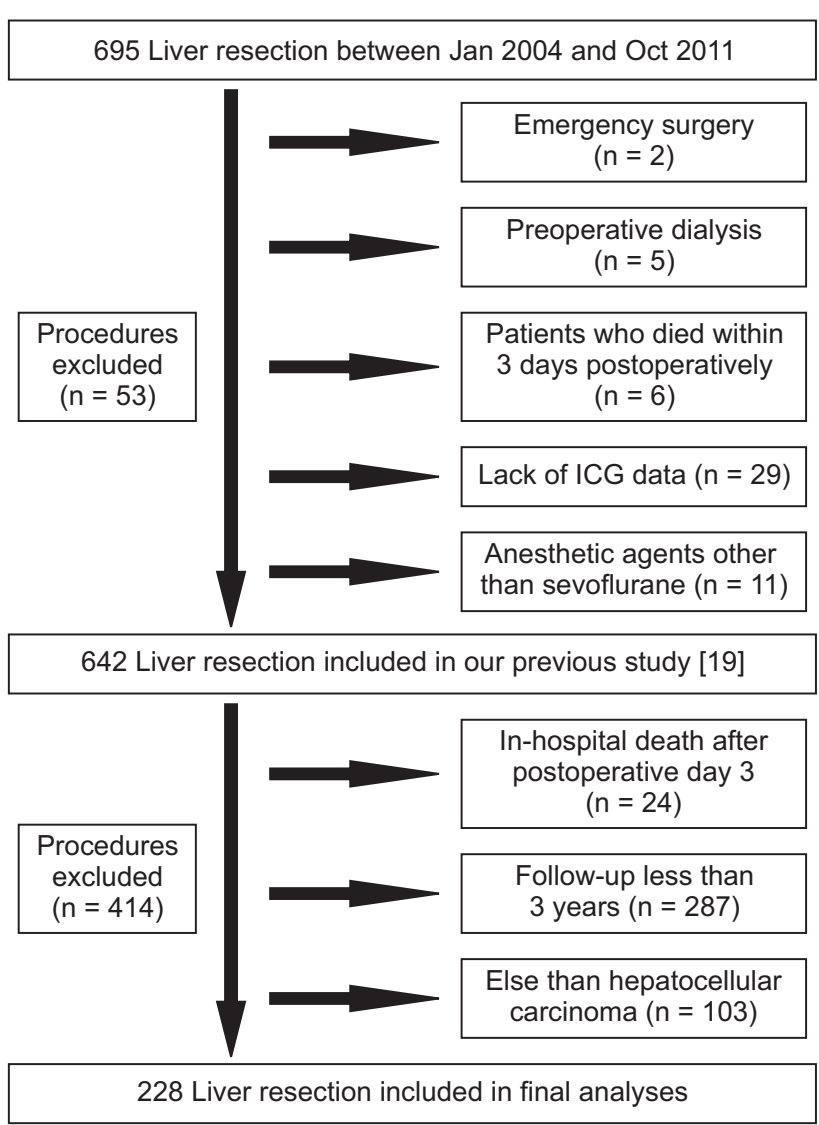

Fig. 1. Flow chart outlining the inclusion and exclusion criteria used in this study. Of the 642 patients included in our previous study, 414 were excluded, leaving 228 patients in the final analysis.

to model the relationship between clinical outcomes, including mortality within 3 years after discharge, and perioperative risk factors. The following factors were selected a priori based on their potential association with mortality: age, pre-existing renal failure (preoperative eGFR), pre-existing liver failure (preoperative ICG-R15), major resection, intraoperative red blood cell transfusion (number of units), postoperative AKI, and cancer stage. Since only a few patients were TNM stage IV, stages III and IV were combined for the multivariate analysis. To avoid multicollinearity, we did not simultaneously include two or more predictor variables that were highly correlated $(r>0.8)$ in the multivariate analysis model.

All tests were two-sided, and we considered a $\mathrm{P}$ value $<0.05$ 
Table 2. Preoperative Patient Characteristics and Intraoperative Variables by AKI Status

\begin{tabular}{|c|c|c|c|c|}
\hline & $\begin{array}{l}\text { All patients } \\
(\mathrm{n}=228)\end{array}$ & $\begin{array}{l}\text { AKI patients } \\
(\mathrm{n}=27)\end{array}$ & $\begin{array}{l}\text { Non-AKI patients } \\
\quad(\mathrm{n}=201)\end{array}$ & $\mathrm{P}$ value \\
\hline Age (yr) & $67.4 \pm 8.9$ & $70.0 \pm 8.1$ & $67.0 \pm 8.9$ & 0.097 \\
\hline Female & $57(25)$ & $5(19)$ & $52(26)$ & 0.485 \\
\hline Height $(\mathrm{cm})$ & $161.5 \pm 9.1$ & $162.8 \pm 8.6$ & $161.3 \pm 9.1$ & 0.435 \\
\hline Body weight $(\mathrm{kg})$ & $62.5 \pm 12.0$ & $62.8 \pm 13.1$ & $62.5 \pm 11.9$ & 0.909 \\
\hline BMI $\left(\mathrm{kg} / \mathrm{m}^{2}\right)$ & $23.9 \pm 3.5$ & $23.5 \pm 3.7$ & $23.9 \pm 3.5$ & 0.567 \\
\hline ASA & & & & 0.775 \\
\hline 1 & $3(1)$ & $0(0)$ & $3(1)$ & \\
\hline 2 & $196(86)$ & $23(85)$ & $173(86)$ & \\
\hline 3 & $29(13)$ & $4(15)$ & $25(12)$ & \\
\hline 4 & $0(0)$ & $0(0)$ & $0(0)$ & \\
\hline 5 & $0(0)$ & $0(0)$ & $0(0)$ & \\
\hline TNM staging & & & & 0.506 \\
\hline I & $105(46)$ & $11(41)$ & $94(47)$ & \\
\hline II & $84(37)$ & $9(33)$ & $75(37)$ & \\
\hline IIIA or IIIB or IIIC & $37(16)$ & $7(26)$ & $30(15)$ & \\
\hline IVA or IVB & $2(1)$ & $0(0)$ & $2(1)$ & \\
\hline \multicolumn{5}{|l|}{ Baseline laboratory values } \\
\hline Hemoglobin (g/dl) & $13.0 \pm 1.8$ & $12.2 \pm 2.1$ & $13.1 \pm 1.8$ & 0.021 \\
\hline Creatinine $(\mathrm{mg} / \mathrm{dl})$ & $0.8 \pm 0.3$ & $1.0 \pm 0.4$ & $0.8 \pm 0.2$ & $<0.001$ \\
\hline $\mathrm{eGFR}\left(\mathrm{ml} / \mathrm{min} / 1.73 \mathrm{~m}^{2}\right)$ & $73.6 \pm 19.7$ & $64.3 \pm 23.1$ & $74.8 \pm 18.9$ & $<0.001$ \\
\hline Albumin $(\mathrm{g} / \mathrm{dl})$ & $3.9 \pm 0.5$ & $3.8 \pm 0.5$ & $4.0 \pm 0.5$ & 0.044 \\
\hline Total bilirubin (mg/dl) & $0.9 \pm 0.4$ & $0.8 \pm 0.4$ & $0.9 \pm 0.4$ & 0.610 \\
\hline GOT (IU/L) & $42(29-63)$ & $51(30-63)$ & $41(29-62)$ & 0.392 \\
\hline GPT (IU/L) & $37(25-58)$ & $35(25-59)$ & $38(25-57)$ & 0.976 \\
\hline Platelet count $(/ \mu \mathrm{l})$ & $15.6 \pm 7.0$ & $15.0 \pm 9.8$ & $15.7 \pm 6.5$ & 0.664 \\
\hline ICG-R15 min (\%) & $19.1 \pm 11.3$ & $19.5 \pm 10.9$ & $19.0 \pm 11.4$ & 0.818 \\
\hline \multicolumn{5}{|l|}{ Comorbidities } \\
\hline Hypertension & $126(55)$ & $19(70)$ & $107(53)$ & 0.103 \\
\hline Ischemic heart disease & $18(8)$ & $2(7)$ & $16(8)$ & 1.000 \\
\hline Atrial fibrillation & $11(5)$ & $1(4)$ & $10(5)$ & 1.000 \\
\hline Cerebrovascular disease & $17(7)$ & $2(7)$ & $15(7)$ & 1.000 \\
\hline Diabetes mellitus & & & & 0.460 \\
\hline No diabetes & $169(74)$ & $18(67)$ & $151(75)$ & \\
\hline Oral medication & $28(12)$ & $5(19)$ & $23(11)$ & \\
\hline Insulin therapy & $31(14)$ & $4(15)$ & $27(13)$ & \\
\hline Hyperlipidemia & $17(7)$ & $2(7)$ & $15(7)$ & 1.000 \\
\hline COPD & $26(11)$ & $4(15)$ & $22(11)$ & 0.523 \\
\hline Liver cirrhosis & $44(19)$ & $9(33)$ & $35(17)$ & 0.067 \\
\hline Peripheral vascular disease & $6(3)$ & $3(11)$ & $3(1)$ & 0.023 \\
\hline \multicolumn{5}{|l|}{ Preoperative medications } \\
\hline NSAIDs & $6(3)$ & $0(0)$ & $6(3)$ & 1.000 \\
\hline ACE inhibitors & $21(9)$ & $1(4)$ & $20(10)$ & 0.482 \\
\hline $\mathrm{ARB}$ & $45(20)$ & $7(26)$ & $38(19)$ & 0.439 \\
\hline Statin & $8(4)$ & $2(7)$ & $6(3)$ & 0.242 \\
\hline Diuretics & $23(10)$ & $3(11)$ & $20(10)$ & 0.741 \\
\hline \multicolumn{5}{|l|}{ Intraoperative variables } \\
\hline Adjuvant epidural & $188(82)$ & $19(70)$ & $169(84)$ & 0.103 \\
\hline Lowest mean SBP (mmHg) & $76.2 \pm 11.1$ & $72.1 \pm 15.1$ & $76.8 \pm 10.3$ & 0.039 \\
\hline $\mathrm{EBL}(\mathrm{ml})$ & $1122(579-2211)$ & $1864(1015-3726)$ & $1038(568-2144)$ & $<0.001$ \\
\hline \multicolumn{5}{|l|}{ Intraoperative fluids } \\
\hline Crystalloid (ml) & $4195(2960-5635)$ & $4750(3650-6620)$ & $4110(2900-5470)$ & 0.063 \\
\hline Received HES & $47(21)$ & $3(11)$ & $44(22)$ & 0.309 \\
\hline \multicolumn{5}{|l|}{ Intraoperative transfusions } \\
\hline Received RBCs & $68(30)$ & $14(52)$ & $54(27)$ & 0.013 \\
\hline Units of RBCs & $0(0-2)$ & $2(0-6)$ & $0(0-2)$ & $<0.001$ \\
\hline Received FFP & $72(32)$ & $14(52)$ & $58(29)$ & 0.026 \\
\hline Received platelets & $28(12)$ & $9(33)$ & $19(9)$ & 0.002 \\
\hline \multicolumn{5}{|l|}{ Surgical procedure } \\
\hline Major resection & $53(23)$ & $9(33)$ & $44(22)$ & 0.224 \\
\hline Duration of surgery (min) & $284 \pm 93$ & $298 \pm 89$ & $283 \pm 93$ & 0.420 \\
\hline Duration of anesthesia (min) & $349 \pm 94$ & $361 \pm 91$ & $347 \pm 94$ & 0.499 \\
\hline
\end{tabular}

Values are mean $\pm \mathrm{SD}$, median (interquartile range) or number of patients (\%). AKI: acute kidney injury, BMI: body mass index, ASA: American Society of Anesthesiologists, TNM: tumor, node, metastasis, eGFR: estimated glomerular filtration rate, GOT: glutamic oxaloacetic transaminase, GPT: glutamic pyruvic transaminase, ICG-R15 min: indocyanine green retention at 15 minutes, COPD: chronic obstructive pulmonary disease, NSAIDs: nonsteroidal anti-inflammatory drugs, ACE: angiotensin-converting enzyme, ARB: angiotensin II receptor blockers, SBP: systolic blood pressure, EBL: estimated blood loss, HES: hydroxyethyl starch, RBCs: red blood cells, FFP: fresh frozen plasma. 
to be statistically significant. The statistical analyses were performed using STATA software (ver. 13; StataCorp., College Station, TX, USA).

\section{Results}

In total, this study identified 695 patients who underwent liver resection between January 2004 and October 2011. After excluding 53 patients in our previous study [19], a further 414 patients were excluded for the reasons shown in Fig. 1, leaving 228 patients for the final analysis. AKI based on the AKIN criteria occurred in 27 patients (11.8\%) within the first 72 hours, with all patients being classified as either AKIN stage $1(n=22)$ or $2(n=5)$. No patients classified as AKIN stage 3 were included in the final analysis.
Patients who developed AKI had significantly lower preoperative hemoglobin concentrations, higher sCr levels, lower eGFR, and lower serum albumin concentrations. AKI patients were more likely than non-AKI patients to have peripheral vascular disease. The lowest SBP during anesthesia was significantly lower in AKI patients than in non-AKI patients (Table 2).

Although the estimated blood loss was significantly greater in AKI patients than in non-AKI patients, there were no significant differences in the amount of crystalloid administered or percentage of patients who received HES intraoperatively. The percentage of patients who received transfusions of red blood cells, fresh frozen plasma, and platelets was significantly higher in the AKI group than in the non-AKI group. The percentage of patients who underwent major liver resection did not differ significantly between the AKI and non-AKI patients. The

Table 3. Cox Proportional Hazard Regression Analysis

\begin{tabular}{|c|c|c|c|}
\hline Variable & $\mathrm{HR}$ adj & $95 \% \mathrm{CI}$ & $\mathrm{P}$ value \\
\hline \multicolumn{4}{|c|}{ (A) Factors That Are Related to Mortality within 3 Years after Hospital Discharge } \\
\hline Age in years (per 10 years) & 1.00 & $0.73-1.37$ & 0.990 \\
\hline Preoperative eGFR (per $10 \mathrm{ml} / \mathrm{min} / 1.73 \mathrm{~m}^{2}$ ) & 0.95 & $0.84-1.08$ & 0.427 \\
\hline Preoperative ICG-R15 min, \% (SD) & 1.01 & $0.99-1.03$ & 0.190 \\
\hline Major resection* & 1.30 & $0.70-2.43$ & 0.407 \\
\hline Red blood cell transfusion (per unit) ${ }^{\dagger}$ & 1.06 & $1.02-1.10$ & 0.003 \\
\hline Postoperative AKI & 0.87 & $0.42-1.78$ & 0.699 \\
\hline \multicolumn{4}{|l|}{ TNM staging } \\
\hline I (reference) & 1 & & \\
\hline II & 1.59 & $0.86-2.96$ & 0.141 \\
\hline III or IV & 4.07 & $1.98-8.37$ & $<0.001$ \\
\hline \multicolumn{4}{|c|}{ (B) Factors Related to the Composite Outcome of Mortality or eGFR $\leq 60 \mathrm{ml} / \mathrm{min} / 1.73 \mathrm{~m}^{2}$ within 3 Years after Hospital Discharge } \\
\hline Age in years (per 10 years) & 1.20 & $0.97-1.50$ & 0.098 \\
\hline Preoperative eGFR (per $10 \mathrm{ml} / \mathrm{min} / 1.73 \mathrm{~m}^{2}$ ) & 0.70 & $0.64-0.77$ & $<0.001$ \\
\hline Preoperative ICG-R15 min, \% (SD) & 1.01 & $1.00-1.03$ & 0.040 \\
\hline Major resection* & 0.85 & $0.53-1.35$ & 0.483 \\
\hline Red blood cell transfusion (per unit) ${ }^{\dagger}$ & 1.01 & $0.97-1.04$ & 0.684 \\
\hline Postoperative AKI & 1.26 & $0.78-2.03$ & 0.347 \\
\hline \multicolumn{4}{|l|}{ TNM staging } \\
\hline I (reference) & 1 & & \\
\hline II & 1.27 & $0.88-1.81$ & 0.198 \\
\hline III or IV & 2.01 & $1.20-3.38$ & 0.008 \\
\hline \multicolumn{4}{|c|}{ (C) Factors Related to the Composite Outcome of Mortality or eGFR $\leq 45 \mathrm{ml} / \mathrm{min} / 1.73 \mathrm{~m}^{2}$ within 3 Years after Hospital Discharge } \\
\hline Age in years (per 10 years) & 1.35 & $1.03-1.77$ & 0.028 \\
\hline Preoperative eGFR (per $10 \mathrm{ml} / \mathrm{min} / 1.73 \mathrm{~m}^{2}$ ) & 0.75 & $0.67-0.83$ & $<0.001$ \\
\hline Preoperative ICG-R15 min, \% (SD) & 1.01 & $0.99-1.02$ & 0.517 \\
\hline Major resection $*$ & 1.14 & $0.70-1.87$ & 0.604 \\
\hline Red blood cell transfusion (per unit) $^{\dagger}$ & 1.03 & $1.00-1.07$ & 0.088 \\
\hline Postoperative AKI & 1.76 & $1.05-2.96$ & 0.033 \\
\hline \multicolumn{4}{|l|}{ TNM staging } \\
\hline I (reference) & 1 & & \\
\hline II & 1.49 & $0.95-2.35$ & 0.084 \\
\hline III or IV & 2.69 & $1.55-4.67$ & $<0.001$ \\
\hline
\end{tabular}

HR adj: hazard ratio adjusted, eGFR: estimated glomerular filtration rate, ICG-R15 min: 15-minute indocyanine green retention rate, AKI: acute kidney injury, TNM: tumor, node, metastasis. ${ }^{*}$ Defined as a resection of at least three Couinaud liver segments. ${ }^{\dagger}$ One unit of each blood component was derived from $200 \mathrm{ml}$ of whole blood. 
durations of surgery and anesthesia did not differ significantly between the AKI and non-AKI patients (Table 2).

Although the percentages of patients who reached the threshold eGFR of $45 \mathrm{ml} / \mathrm{min} / 1.73 \mathrm{~m}^{2}$ and the composite outcome of mortality or eGFR of $45 \mathrm{ml} / \mathrm{min} / 1.73 \mathrm{~m}^{2}$, within 3 years of hospital discharge in the AKI group, were significantly higher than those in the non-AKI group, there were no significant group differences in the percentages of patients who died or reached the composite outcome of mortality or eGFR of $60 \mathrm{ml} / \mathrm{min} / 1.73 \mathrm{~m}^{2}$ within 3 years. A Cox proportional hazard regression analysis revealed that postoperative AKI was associated with the composite outcome of mortality or an eGFR of $45 \mathrm{ml} / \mathrm{min} / 1.73 \mathrm{~m}^{2}$ (Table 3C), but not with mortality (Table 3A) or the composite outcome of mortality or an eGFR of $60 \mathrm{ml} / \mathrm{min} / 1.73 \mathrm{~m}^{2}$ (Table 3B). Higher TNM staging was independently associated with both mortality (Table 3A) and the composite outcome of mortality or renal dysfunction (Tables 3B and 3C).

\section{Discussion}

We assessed the effects of AKI after liver resection on outcomes within 3 years after discharge by comparing mortality rates, renal dysfunction, and composite outcome of mortality or renal dysfunction between AKI and non-AKI patients. A multivariate Cox proportional hazard regression analysis showed that postoperative AKI was independently associated with the composite outcome of mortality or moderate renal dysfunction (eGFR of $45 \mathrm{ml} / \mathrm{min} / 1.73 \mathrm{~m}^{2}$ ) within 3 years after discharge, but not with mortality or the composite outcome of mortality or mild renal dysfunction (eGFR of $60 \mathrm{ml} / \mathrm{min} / 1.73 \mathrm{~m}^{2}$ ).

Postoperative AKI is associated with worse short-term outcomes (e.g., during hospitalization), including higher mortality rates in both cardiac $[8,11]$ and non-cardiac surgery $[6,10,12]$. However, little is known about the effects of postoperative AKI on long-term outcomes and data are available only for patients who underwent cardiac surgery [9,14], transplantation [22], or major cardiothoracic surgery [13]. To our knowledge, no study has investigated the impact of postoperative AKI on long-term outcomes in patients who underwent major abdominal surgery.

Apart from the surgical setting, recent studies suggest that AKI is not always reversible and may lead to CKD and ESRD in the long term, even after renal function recovers to the baseline level [23]. For example, using a database of 233,803 patients, Ishani et al. [24] demonstrated that elderly patients with AKI are at greater risk of ESRD, suggesting that AKI episodes accelerate the progression of renal disease. The renal function outcomes in patients who survive AKI may include full recovery, incomplete recovery resulting in $\mathrm{CKD}$, exacerbation of pre-existing CKD accelerating the progression to ESRD, and non-recovery of kidney function leading to CKD [23]. It is not clear whether AKI after non-cardiac surgery accelerates the progression to CKD (e.g., eGFR of $45 \mathrm{ml} / \mathrm{min} / 1.73 \mathrm{~m}^{2}$ ), and we believe this is worth investigating.

Although postoperative AKI was significantly associated with the composite outcome of mortality or moderate renal dysfunction, the mechanisms behind worse long-term outcome after liver resection are not clear. In terms of the effects of postoperative AKI on worse long-term outcomes in cardiac patients, one possibility is that potential renal dysfunction may have been unmasked by hypotension or reduced blood flow to the kidneys during cardiac surgery in patients with a normal sCr [25]. It is generally accepted that $\mathrm{sCr}$ is not a sensitive marker of renal dysfunction and is affected by factors such as age, sex, muscle mass, and protein intake [26]. Since the pathogeneses of both coronary heart disease and renal dysfunction are partly related to atherosclerosis, such potential renal dysfunction may be related to more severe heart disease and thereby worse mortality and progression of renal dysfunction. Another possibility is that although increased $\mathrm{sCr}$ is reversible in many cases, renal blood flow and clearance can remain impaired for a prolonged period after an AKI episode. Researchers have demonstrated that ongoing progressive damage after AKI results in a decrease in perpendicular capillary density [27].

The lack of a significant association between AKI after liver resection and mortality (Table $3 \mathrm{~A}$ ) may be explained in part by the malignant nature of the disease. Some patients likely died from their malignancy before postoperative AKI had any effects on renal function. We postulate that malignancy was a more important contributor to mortality than was postoperative AKI.

Since cancer stage was independently associated with mortality in this study, the severity and extent of the malignant diseases may have been related to the worse outcomes. Although AKI may lead to CKD or ESRD, as mentioned previously [23], this assumption may not necessarily apply to patients with malignant diseases.

Several limitations of this study need to be addressed. First, as with all observational research, our results may be explained by residual or unmeasured confounders. Generalizability is limited to centers with patient and surgical profiles similar to our own. Second, approximately $64 \%$ of the patients were excluded from the study, which may have caused potential bias in the patient population included in the final analysis. Lastly, the AKI observed in this study was mostly mild, which may explain why effects of AKI on long-term outcome were not apparent.

In conclusion, postoperative AKI seems to have a significant relationship with the composite outcome of mortality or moderate renal dysfunction within 3 years. These findings suggest that even after patients are discharged from the hospital, renal function may require long-term follow-up in patients who suffered AKI after liver resection. Further studies may be required to 
clarify the relationships between postoperative AKI and worse long-term outcomes in patients undergoing major abdominal surgery.

\section{Acknowledgments}

This work was funded by the Department of Anesthesiology, Tokyo Medical and Dental University, Graduate School of Medical and Dental Sciences, Japan. Dr. Ishikawa is supported through Grant-in-Aid for Scientific Research ((C) 25462426) from Ministry of Education, Culture, Sports, Science and Technology, Japan. The authors declare no conflict of interest associ- ated with this manuscript.

\section{ORCID}

Seiji Ishikawa, https://orcid.org/0000-0002-5044-7789

Manami Tanaka, https://orcid.org/0000-0002-9449-5408

Fumi Maruyama, https://orcid.org/0000-0002-7616-7996

Arisa Fukagawa, https://orcid.org/0000-0002-6300-6165

Nobuhiro Shiota, https://orcid.org/0000-0002-9698-722X

Satoshi Matsumura, https://orcid.org/0000-0002-4682-3366

Koshi Makita, https://orcid.org/0000-0002-1309-8102

\section{References}

1. Carmichael P, Carmichael AR. Acute renal failure in the surgical setting. ANZ J Surg 2003; 73: 144-53.

2. Tang IY, Murray PT. Prevention of perioperative acute renal failure: what works? Best Pract Res Clin Anaesthesiol 2004; 18 : 91-111.

3. Bellomo R, Ronco C, Kellum JA, Mehta RL, Palevsky P. Acute renal failure - definition, outcome measures, animal models, fluid therapy and information technology needs: the Second International Consensus Conference of the Acute Dialysis Quality Initiative (ADQI) Group. Crit Care 2004; 8: R204-12.

4. Mehta RL, Kellum JA, Shah SV, Molitoris BA, Ronco C, Warnock DG, et al. Acute Kidney Injury Network: report of an initiative to improve outcomes in acute kidney injury. Crit Care 2007; 11: R31.

5. Moore EM, Simpson JA, Tobin A, Santamaria J. Preoperative estimated glomerular filtration rate and RIFLE-classified postoperative acute kidney injury predict length of stay post-coronary bypass surgery in an Australian setting. Anaesth Intensive Care 2010; 38 : 113-21.

6. Bennet SJ, Berry OM, Goddard J, Keating JF. Acute renal dysfunction following hip fracture. Injury 2010; 41: 335-8.

7. Thakar CV, Kharat V, Blanck S, Leonard AC. Acute kidney injury after gastric bypass surgery. Clin J Am Soc Nephrol 2007; 2: 426-30.

8. Lassnigg A, Schmid ER, Hiesmayr M, Falk C, Druml W, Bauer P, et al. Impact of minimal increases in serum creatinine on outcome in patients after cardiothoracic surgery: do we have to revise current definitions of acute renal failure? Crit Care Med 2008; 36: 1129-37.

9. Bihorac A, Yavas S, Subbiah S, Hobson CE, Schold JD, Gabrielli A, et al. Long-term risk of mortality and acute kidney injury during hospitalization after major surgery. Ann Surg 2009; 249: 851-8.

10. Abelha FJ, Botelho M, Fernandes V, Barros H. Determinants of postoperative acute kidney injury. Crit Care 2009; 13 : R79.

11. Karkouti K, Wijeysundera DN, Yau TM, Callum JL, Cheng DC, Crowther M, et al. Acute kidney injury after cardiac surgery: focus on modifiable risk factors. Circulation 2009; 119: 495-502.

12. Kheterpal S, Tremper KK, Heung M, Rosenberg AL, Englesbe M, Shanks AM, et al. Development and validation of an acute kidney injury risk index for patients undergoing general surgery: results from a national data set. Anesthesiology 2009; 110: 505-15.

13. Hobson CE, Yavas S, Segal MS, Schold JD, Tribble CG, Layon AJ, et al. Acute kidney injury is associated with increased long-term mortality after cardiothoracic surgery. Circulation 2009; 119: 2444-53.

14. Hansen MK, Gammelager H, Mikkelsen MM, Hjortdal VE, Layton JB, Johnsen SP, et al. Post-operative acute kidney injury and five-year risk of death, myocardial infarction, and stroke among elective cardiac surgical patients: a cohort study. Crit Care 2013; 17: R292.

15. Bucaloiu ID, Kirchner HL, Norfolk ER, Hartle JE 2nd, Perkins RM. Increased risk of death and de novo chronic kidney disease following reversible acute kidney injury. Kidney Int 2012; 81: 477-85.

16. Shirabe K, Kajiyama K, Harimoto N, Tsujita E, Wakiyama S, Maehara Y. Risk factors for massive bleeding during major hepatectomy. World J Surg 2010; 34: 1555-62.

17. Jones DR, Lee HT. Perioperative renal protection. Best Pract Res Clin Anaesthesiol 2008; 22: 193-208.

18. von Elm E, Altman DG, Egger M, Pocock SJ, Gøtzsche PC, Vandenbroucke JP. The Strengthening the Reporting of Observational Studies in Epidemiology (STROBE) statement: guidelines for reporting observational studies. Ann Intern Med 2007; 147: 573-7.

19. Tomozawa A, Ishikawa S, Shiota N, Cholvisudhi P, Makita K. Perioperative risk factors for acute kidney injury after liver resection surgery: an historical cohort study. Can J Anaesth 2015; 62: 753-61.

20. Matsuo S, Imai E, Horio M, Yasuda Y, Tomita K, Nitta K, et al. Revised equations for estimated GFR from serum creatinine in Japan. Am J Kidney Dis 2009; 53: 982-92.

21. Kalamas AG, Niemann CU. Patients with chronic kidney disease. Med Clin North Am 2013; 97: 1109-22.

22. Jacques F, El-Hamamsy I, Fortier A, Maltais S, Perrault LP, Liberman M, et al. Acute renal failure following lung transplantation: risk factors, mortality, and long-term consequences. Eur J Cardiothorac Surg 2012; 41: 193-9. 
23. Okusa MD, Chertow GM, Portilla D. The nexus of acute kidney injury, chronic kidney disease, and World Kidney Day 2009. Clin J Am Soc Nephrol 2009; 4: 520-2.

24. Ishani A, Xue JL, Himmelfarb J, Eggers PW, Kimmel PL, Molitoris BA, et al. Acute kidney injury increases risk of ESRD among elderly. J Am Soc Nephrol 2009; 20: 223-8.

25. Ishani A, Nelson D, Clothier B, Schult T, Nugent S, Greer N, et al. The magnitude of acute serum creatinine increase after cardiac surgery and the risk of chronic kidney disease, progression of kidney disease, and death. Arch Intern Med 2011; 171: 226-33.

26. Augoustides JG. Serum creatinine as a perioperative biomarker: a challenge for perioperative management and an opportunity for the Cardiothoracic Surgery Trials Network. J Thorac Cardiovasc Surg 2012; 143: 523-4.

27. Basile DP. Rarefaction of peritubular capillaries following ischemic acute renal failure: a potential factor predisposing to progressive nephropathy. Curr Opin Nephrol Hypertens 2004; 13: 1-7. 